\title{
Empresarios agrícolas y campesinos colonos: colonización y conflicto agrario en la frontera antioqueña $(1926-1947)^{*}$
}

\begin{abstract}
Diana Henao Holguín
Profesora auxiliar del Instituto de Historia y Ciencias Sociales de la Universidad Austral de Chile. Correo electrónico: diana.henao@uach.cl. La autora es doctora en Historia por la Universidad de Santiago de Chile. Forma parte del equipo de gestión del Seminario Internacional sobre Historia de la Violencia en América Latina. Entre sus publicaciones recientes destacamos: "Gamonalismo y redes de poder local en el Nordeste antioqueño (Colombia). 1930-1953”, Revista Tempo e Argumento (2019) y “Frontera y Raza: La colonización de tierras públicas en Antioquia (Colombia) durante la primera mitad del siglo XX". En Fragmentos de identidade e cultura (São Paulo: Editorial Todas as Musas, 2018). Entre sus temas de interés están la historia del mundo agrario colombiano, el bandolerismo rural y la conflictividad social y política.
\end{abstract}

Recibido: 17 de enero de 2020

Aprobado: 27 de abril de 2020

Modificado: 14 de mayo de 2020

Artículo de investigación científica

DOI: https://doi.org/10.15648/hc.39.2021.2951

Este artículo forma parte del proyecto "Luchas por la tierra Colonización y conflicto agrario en Antioquia (Colombia) 1930-1953" financiado por VRIDEI-DICYT. Universidad de Santiago de Chile. Esta publicación está bajo una licencia Creative Commons Reconocimiento-NoComercial 4.0 
Empresarios agrícolas y campesinos colonos: colonización y conflicto agrario en la frontera antioqueña (1926-1947)

\title{
Resumen
}

El artículo analiza los conflictos entre empresarios agrícolas y campesinos colonos en el marco de la colonización hacia el Magdalena Medio antioqueño. Estos conflictos se estudian en el ciclo de protesta campesina que va de 1926 a 1947. Este periodo se caracterizó por el uso del aparato legal por parte de los actores que ocuparon la frontera. No obstante, también hubo expresiones de violencia que buscaron impedir la adjudicación de tierras. La conflictividad en esta zona es dinámica puesto que, no se dio solo de arriba hacia abajo, sino también de manera horizontal entre los sectores involucrados.

Palabras clave: frontera agrícola, conflicto agrario, empresarios agrícolas, campesinos colonos, violencia.

Agricultural entrepreneurs and colonist farmers: colonization and agrarian conflict in the Antioquia border (1926-1947)

\begin{abstract}
This article analyses the conflicts between agricultural entrepreneurs and colonist farmers within the colonization context towards the region of Magdalena Medio in Antioquia. These conflicts are studied in the farmer protests cycle from 1926 to 1947. This period was characterized by the use of the legal apparatus by those actors who occupied the border. Nevertheless, there were also expressions of violence seeking to prevent the distribution of the land. Contentiousness in this area is dynamic because it arises not only from top to bottom, but also in horizontally among all sectors involved.
\end{abstract}

Key words: agrarian border, agrarian conflict, agricultural entrepreneurs, colonists' farmers, violence.

Empresários Agrícolas e Colonos Camponeses: Colonização e Conflito Agrícola na fronteira Antioqueña (1926-1947)

\section{Resumo}

O artigo analisa os conflitos entre empresários agrícolas e colonos camponeses 
no processo da colonização ao Magdalena Medio Antioqueño. Esses conflitos são estudados no ciclo de protestos camponeses que vai de 1926 até 1947 . Esse período foi caracterizado pelo uso do aparato legal pelos atores que ocupavam a fronteira. No entanto, também houve expressões de violência que procuravam impedir a adjudicação de terras. O conflito nessa área é dinâmico, pois, não foi só de cima para baixo, mas também horizontalmente entre os setores envolvidos.

Palavras-chave: fronteira agrícola, conflito agrário, empresários agrícolas, colonos camponeses, violência.

\section{Entrepreneurs Agricoles et Paysans Colons: Colonisation et Conflit Agraire} À la frontière de L'Antioquia (1926-1947)

\section{Résumé}

L'article analyse les conflits entre entrepreneurs agricoles et paysans colons dans le cadre de la colonisation vers la région du Magdalena Medio à Antioquia. Ces conflits sont étudiés dans le cycle de protestation paysanne de 1926 à 1947. Cette période a été marquée par l'utilisation de l'appareil juridique par les acteurs qui ont occupé la frontière. Mais il y aura aussi des manifestations de violence qui ont cherché à empêcher l'attribution de terres. Les conflits dans cette zone sont dynamiques car ils se sont produits non seulement de haut en bas, mais aussi horizontalement entre les secteurs concernés.

Mots clés: frontière agricole, conflits agraires, entrepreneurs agricoles, violence.

\section{INTRODUCCIÓN}

La historiografía colombiana ha estudiado ampliamente los procesos de expansión de la frontera agrícola y los conflictos por la tierra asociados a la colonización de tierras públicas. Dicha historiografía sostiene que la ocupación de tierras baldías en Colombia se dio en dos etapas. En la primera, hombres y mujeres se desplazaron hacia las fronteras agrícolas internas, mejorando la tierra por medio de su trabajo. En la segunda etapa, los empresarios agrícolas se apropiaron de la tierra y del trabajo campesino y empezaron a consolidar nuevas haciendas ${ }^{1}$. En

1 Catherine LeGrand, Colonización y protesta campesina en Colombia. 1850-1950 (Bogotá: Universidad Nacional de Colombia, 1988). 
consecuencia, la ocupación de tierras públicas ha sido un proceso de larga duración que ha configurado unas relaciones conflictivas entre los distintos actores que históricamente han colonizado las fronteras internas. Cabe anotar que, la colonización no ha sido exclusiva del caso colombiano, los países latinoamericanos también vivieron desplazamientos de población, los cuales coincidieron con su ingreso a la economía mundial. En muchas ocasiones estas zonas correspondieron a los lugares económicamente más productivos, por tanto, fueron vistos como espacios de riqueza que debían ser anexados a los mercados nacionales e internacionales.

Vale la pena mencionar los casos de Brasil, Costa Rica y Venezuela, países que como Colombia, se integraron a la economía capitalista por medio de la exportación del café. La expansión del cultivo del café dependió de la migración de población hacia las tierras públicas y el establecimiento de nuevos territorios en las zonas de frontera, en donde se establecieron sistemas de trabajo y patrones de tenencia de la tierra que variaron de un país a otro. No obstante, un aspecto central es el rol del Estado en el traspaso de tierras públicas a individuos privados. En Brasil, por ejemplo, la promulgación de la Ley de Tierras de 1850 buscaba regular la situación de los títulos, además de estimular la inmigración. En los primeros artículos se establecía que la adquisición de tierras públicas debía hacerse a través de compra; además determinó la forma en que particulares podían convertirse en propietarios plenos. Sin embargo, la ley hizo inoperante la posesión y terminó propiciando la formación de grandes latifundios ${ }^{2}$.

En contraste con este proceso se encuentra el de Costa Rica, en donde hubo una política estatal que favoreció a los pequeños propietarios en la adquisición de tierras, por lo que sus luchas se enfocaron más en los problemas de acceso al crédito, que en los procesos de acaparamiento de la tierra por parte de las élites y sus aliados políticos ${ }^{3}$. Por su parte, los procesos de ocupación de baldíos en Venezuela y Colombia ocurrieron

2 Ligia María Osorio Silva, "Tierras nuevas y la construcción del Estado en Brasil y Argentina”, América Latina en la Historia Económica, No. 25 (2006): 45-71.

3 Mario Samper, Generations of Settlers. Rural households and markets on the Costa Rican frontier, 1850-1935 (San Francisco: Westview Press. Dellplain Latin American Studies, No. 26, 1990). 
de manera similar. En ambos países, hacia mediados del siglo XIX, los colonos migraron a las zonas de frontera, transformando y mejorando la tierra de amplias zonas baldías, que posteriormente fueron apropiadas por las élites y los empresarios agrícolas ${ }^{4}$.

Ahora bien, los trabajos de historia agraria colombiana se han enfocado en el análisis de los conflictos asociados a la colonización en las zonas donde la lucha campesina irrumpió con fuerza. Estas regiones corresponden principalmente a los departamentos de Tolima y Cundinamarca en el centro del país. Allí, el predominio de la hacienda cafetera fue mayor, por lo que las luchas del campesinado se enfocaron en la modificación de los sistemas de trabajo precapitalistas y en la reivindicación de la función social de la tierra, estas luchas culminaron con la desintegración de la hacienda ${ }^{5}$. Paralelamente a este proceso hubo expresiones del conflicto en la zona Caribe, aquí la United Fruit Company y los colonos entraron en conflicto por los predios que le fueron concesionados a la empresa extranjera ${ }^{6}$. Finalmente, se ha prestado mayor atención a la Colonización Antioqueña al occidente del país, proceso que durante varias décadas fue visto como modélico, ya que, en esta región se habría formado una sociedad democrática y próspera de pequeños propietarios en torno al cultivo del café 7 . No obstante, en la

4 Doug Yarrington, "Public Land Settlement, Privatization, and Peasant Protest in Duaca, Venezuela, 1870-1936", Hispanic American Historical Review Vol. 74 No. 1 (1994): 33-61.

5 Marco Palacios, ¿De quién es la tierra? Propiedad, politización y protesta campesina en la década de 1930 (Bogotá: Fondo de Cultura Económica, Universidad de Los Andes, 2011); Marco Palacios, El café en Colombia, 1850-1970. Una historia económica, social y política (Bogotá: El Colegio de México-El Áncora Editores, 1983); Rocío Londoño, Juan de la Cruz Varela. Sociedad y política en la región de Sumapaz (1902-1984) (Bogotá: Universidad Nacional de Colombia, 2011); Elsy Marulanda, Colonización y conflicto. Las lecciones del Sumapaz (Bogotá: Tercer Mundo Editores, IEPRI, 1991); José Jairo González y Elsy Marulanda, Historias de frontera. Colonización y guerra en el Sumapaz (Bogotá: CINEP, 1990); Renzo Ramírez Bacca, "Formación de una hacienda cafetera: mecanismos de organización empresarial y relaciones administrativo-laborales: el caso de La Aurora (Líbano-Colombia), 1882-1907”, Cuadernos de Desarrollo Rural Vol. 42 No. 42 (1999): 83-115; Michael Jiménez, "Traveling Far in Grandfather's Car: The Life Cycle of Central Colombian Coffee Estates. The Case of Viotá, Cundinamarca (1900-1930)", Hispanic American Historical Review Vol. 69 No. 2 (1989): 185-219; Michael F. Jiménez, "En el festín de la civilización: los límites de la hegemonía de los hacendados a comienzos del siglo XX en Colombia", Innovar. Revista de ciencias administrativas y Sociales, 1996, 113-33.

6 Catherine LeGrand, "Campesinos asalariados en la zona bananera de Santa Marta", Anuario Colombiano de Historia Social y de la Cultura No. 11 (1983): 235-50; Hermes Tovar Pinzón, "Los baldíos y el problema agrario en la Costa Caribe de Colombia (1830-1900)", Fronteras de la Historia Vol. 1 (1997): 35-55.

7 James Parsons, Antioqueño Colonization in Western Colombia (Berkeley: University of California 
década de los ochenta se empezó a cuestionar esta visión y se puso de manifiesto el conflicto entre los grandes concesionarios de tierras y los colonos de la zona cafetera ${ }^{8}$.

Colonización y violencia han sido variables fundamentales en el estudio de la historia agraria nacional. Este artículo se inscribe bajo esta línea historiográfica y analiza los conflictos entre empresarios agrícolas y campesinos colonos en una zona de frontera del departamento de Antioquia: el Magdalena Medio, centrándose en los años que van de 1926 a 1947, periodo en el que el proceso de colonización fue jalonado en buena medida por los avances en comunicación y transporte, que permitieron explotar la tierra y conformar grandes haciendas agrícolas y ganaderas en esta subregión. Sin duda, una de las vías de comunicación más importantes fue el Ferrocarril de Antioquia, vital para unir a Medellín con el río Magdalena, principal vía fluvial del país. El ferrocarril sirvió para sacar el café sembrado en las regiones centrales del departamento hacia Puerto Berrío y a la par para transportar el ganado desde el Puerto hacia la feria de ganado en Medellín, una de las más importantes del país.

La relevancia de este artículo no radica solamente en analizar una región y un periodo poco estudiados por la historiografía agraria, sino en que el Magdalena Medio posee unas particularidades. En primer lugar, a diferencia de las regiones centrales del país, en donde la colonización inició a mediados del siglo XIX, en esta zona el proceso fue más tardío? En general, las zonas de frontera del departamento de Antioquia correspondientes al Magdalena Medio, al Bajo Cauca, Nordeste y Urabá siempre constituyeron una preocupación para las élites del centro de Antioquia, quienes movidas por los recursos naturales que allí existen,

8 Keith H Christie, "Antioqueño Colonization in Western Colombia : A Reappraisal", The Hispanic American Historical Review. Vol. 58 No. 2 (1978): 260-83; Roberto Luis Jaramillo, "La otra cara de la colonización antioqueña hacia el sur", s. f.; Nancy Appelbaum, "Whitening the Region: Caucano Mediation and "Antioqueño Colonization" in Nineteenth- "Century Colombia", The Hispanic American Historical Review. Vol. 79 No. 4 (1999): 631-67, www.jstor.org/stable/2518165.

9 El poblamiento de estas subregiones se hizo más fuerte en la primera mitad del siglo XX, sin embargo, esto no significa que estos territorios fueran "tierras vacías" o "espacios de nadie". Estas subregiones han sido testigos de un proceso de poblamiento de larga data, en el que pueden diferenciarse distintas olas migratorias y momentos de ocupación del territorio. 
quisieron generar una colonización planeada hacia estos lugares, en donde se reprodujeran los valores culturales del centro del departamento. Sin embargo, la expansión de las élites solamente ocurrió en la primera mitad del siglo XX. En este sentido, estamos frente a un escenario de configuración territorial en donde el peso del sistema hacendatario heredado del siglo XIX no fue el mismo que en el centro del país, por tanto, las luchas campesinas no iniciaron por la modificación de los sistemas de trabajo, sino que se dieron en el marco de la dinámica de denuncio y adjudicación de tierras públicas, en el que la función social de la tierra cobró importancia. Asimismo, esta subregión no tuvo vocación cafetera, sino que en ella primó la economía ganadera y la agricultura, además de la extracción de minerales y maderas, lo que sin duda le dio un tinte diferenciador al proceso de adjudicación y los conflictos derivados de esta dinámica.

La hipótesis que guía este análisis afirma que el periodo que va de 1926 a 1947, estuvo marcado por la promulgación de leyes que buscaron impulsar la colonización de la frontera agrícola. Asimismo, durante estos años el campesinado se caracterizó por su tradición legalista en la búsqueda de la resolución de sus conflictos agrarios. No obstante, esta conflictividad en algunas ocasiones se expresó de manera violenta, no solamente entre empresarios agrícolas y colonos, sino también de manera horizontal, lo que hace que el conflicto en el Magdalena Medio sea dinámico e involucre diversos actores más allá de los estudiados hasta el momento por la historiografía agraria.

Esta hipótesis se estableció a partir de la revisión de archivos históricos regionales, en los que se estudió principalmente documentación de la serie Minas y Baldíos, en los que se encuentran los expedientes de denuncios de tierras, tanto de adjudicatarios de pequeña cuantía, como los de mediana y gran cuantía ${ }^{10}$. Es decir, colonos que aspiraban obtener,

10 Los cultivadores de pequeña cuantía eran campesinos que querían acceder a adjudicaciones de sus predios por un área no mayor de 20 hectáreas. En la década del cuarenta la legislación cambió y podían acceder a lotes de hasta 50 hectáreas. Los adjudicatarios de mediana y gran cuantía debían realizar otro procedimiento, si querían acceder a lotes de más de 50 hectáreas. Todos los que se sometían a los denuncios de tierras, debían contar con casas de habitación en los terrenos, además de cultivos permanentes y tener cultivada la mitad del terreno a denunciar. Por ello, frente al Estado quienes cumplían con esos requisitos eran colonos. 
después de la respectiva adjudicación, los títulos de tierras. En estos expedientes de baldíos, se observa la participación de distintos sujetos en las dinámicas de ocupación de las fronteras agrícolas, quienes entran en contradicción por la apropiación de los recursos, especialmente por la tierra ${ }^{11}$. Frente al Estado todos los sujetos que hacían denuncios, ya fuera como cultivadores u ocupantes con ganado, eran colonos, puesto que, cumplían los requisitos para levantar los denuncios: establecerse con casa de habitación y tener cultivos permanentes. Sin embargo, en este artículo se hace una diferenciación entre los colonos que denunciaban a título de pequeño cultivador y empresarios agrícolas, quienes debían realizar un procedimiento un poco más complejo. Son estos dos grupos principales los que entran en contradicción. Aunque como se verá, hay otros grupos intermedios que también participan en las dinámicas de la colonización de tierras públicas. Se advierte que a lo largo del escrito colono y campesino a veces son palabras usadas en el mismo sentido.

\section{Colonización y CONFORMación DE LA HACIENDA GANADERA EN el Magdalena Medio}

La historiografía ha identificado un ciclo de protesta campesina entre 1926 y 1936, años marcados por la presión del campesinado en la modificación de los sistemas de trabajo y por la reivindicación de la función social de la tierra ${ }^{12}$. Durante estos años se promulgaron importantes leyes que impulsaron la colonización de tierras públicas. La primera de ellas fue la ley 47 de 1926, que estableció el procedimiento formal para el denuncio y adjudicación de baldíos que rigió hasta la década del cuarenta y que, además, facilitó el procedimiento gracias a la eliminación del papel sellado y la derogación de la obligatoriedad por parte de los testigos, que acompañaban la declaración del denunciante, de

11 Del fondo Minas y Baldíos, se revisaron 129 expedientes que cubren los años de 1926 a 1947 y que corresponden a las actuales subregiones del Magdalena Medio, Nordeste y Bajo Cauca antioqueños. De estos 68 corresponden al Magdalena Medio, especialmente a Puerto Berrío.

12 Renan Vega Cantor, "Las luchas agrarias en Colombia en la década de 1920", Cuadernos de desarrollo rural No. 52 (2004): 9-47, http://revistas.javeriana.edu.co/index.php/desarrollorural/article/ view/1264; Donny Meertens, Ensayos sobre tierra, violencia y género. Hombres y mujeres en la historia rural de Colombia. 1930-1990 (Bogotá: Universidad Nacional de Colombia, 2000); LeGrand, Colonización y protesta campesina en Colombia. 1850-1950. 
poseer propiedad raíz. La ley que cierra este periodo es la 200 de 1936 que estableció la función social de la tierra. Estas leyes tuvieron limitaciones puesto que, no se basaron en la redistribución de la tierra, sino que más bien, impulsaron la colonización de tierras públicas. Por ello, durante estos años se observa una aceleración en el ritmo de las adjudicaciones, que estuvo acompañada de luchas campesinas y conflictos entre empresarios agrícolas y colonos. De acuerdo con la historiografía agraria esta conflictividad llegaría a su fin tras la promulgación de la Ley 200. De ahí que se considere que estos años corresponden a uno de los más importantes ciclos de protesta campesina.

En el Magdalena Medio, de la misma manera que en otras regiones del país, el campesinado y los empresarios agrícolas entraron en contradicción. No obstante, esta conflictividad no se verá interrumpida por la promulgación de la ley de 1936. En esta subregión se observa que, entre 1926 y 1947 hubo una continuidad en los conflictos y los medios de resolución. Así, la dinámica de adjudicación de baldíos y la conflictividad agraria asociada solo se verá interrumpida por los cambios en la legislación en 1946 y por la irrupción de la violencia en la región. En consecuencia, el ciclo de protesta campesina en esta zona se extenderá hasta 1947, cuando los conflictos a nivel local tienen un tinte político y las disputas entre liberales y conservadores de distintas facciones se hacen más recurrentes, aunque el trasfondo de la conflictividad sigue siendo el acceso a la tierra y a otros recursos naturales por los cuales distintos actores entran en disputa.

Como ya se advirtió los procesos de colonización hacia el Magdalena Medio se dieron a finales del siglo XIX, y fueron impulsados por el interés de ampliar las rutas de mercado tanto interno como externo ${ }^{13}$. De esta manera se incorporaron tierras baldías al departamento de Antioquia, las cuales tuvieron un marcado énfasis ganadero, jalonado por la introducción de pastos Guinea y Pará. No obstante, aquí también hubo una importante presencia de compañías nacionales y extranjeras, que se abocaron a la exploración y explotación de petróleo.

13 José Roberto Álvarez Múnera, "Empresas rurales en Antioquia. La ganadería en el Oriente y el Magdalena Medio entre 1920 y 1960" (tesis de doctorado en Ciencias Sociales en la Universidad de Antioquia, 2013). 
La configuración de la hacienda, particularmente en Puerto Berrío, empezó con fuerza en la década del veinte y fue jalonada por el aumento del consumo de carne en la población medellinense, propiciado por un crecimiento económico que reactivó la minería e incrementó la producción cafetera. La historiografía más reciente sobre la ganadería sostiene que esta actividad económica ayudó en la articulación del país. Por medio de la expansión de la frontera agrícola, la producción de ganado estableció lazos entre las regiones de colonización y las zonas centrales desarrollando así un mercado nacional ${ }^{14}$. No obstante, el proceso de colonización al Magdalena Medio deja ver que el acceso a la tierra estuvo restringido a un grupo específico, que tenía la capacidad técnica y económica para realizar el procedimiento de adjudicación de tierras. Además, los recursos suficientes para entrar en litigios por la tierra, como fue el caso de la Sociedad Agrícola y de Inmigración.

En el mapa 1 se pueden observar las adjudicaciones de tierra en las zonas de frontera al oriente del departamento de Antioquia, es decir las subregiones de Bajo Cauca, Magdalena Medio y Nordeste. Los años que cubre el mapa van de 1926, año en que se establece el procedimiento formal de denuncio de baldíos que favoreció a los colonos pequeños, hasta la promulgación de la ley de 1936. Las adjudicaciones del mapa corresponden a las de mediana y gran cuantía y están discriminadas por usos del suelo, se destaca que la mayor parte de los predios se abocó a la ganadería. A primera vista se puede observar que Puerto Berrío se convirtió en una importante zona de colonización.

El conflicto por la tierra y el desplazamiento de colonos ha sido un problema histórico en esta subregión, generado por las extensas concesiones para la construcción de ferrocarriles y carreteras y por el establecimiento de haciendas ganaderas, además, de empresas nacionales y extranjeras dedicadas a la explotación de recursos naturales, principalmente el petróleo ${ }^{15}$.

14 Shawn Ausdal, "Un mosaico cambiante: notas sobre una geografía histórica de la ganadería en Colombia, 1850-1950", en El poder de la carne. Historias de ganaderías en la primera mitad del siglo XX en Colombia (Bogotá: Pontificia Universidad Javeriana, 2008).

15 Lucella Gómez Giraldo, Las fronteras de Antioquia. Aspectos físicos, jurídicos, históricos, económicos y socioculturales (Medellín: Universidad de Antioquia, Fondo editorial FCSH, 2005), 37. 
En esta subregión, los conflictos no fueron solamente verticales, entre colonos y empresarios ganaderos, sino también horizontales entre las mismas élites empresariales, en donde los representantes de la Sociedad Agrícola y de Inmigración tuvieron un papel fundamental. Asimismo, los colonos tuvieron conflictos de manera horizontal. La instalación de nuevas haciendas en la zona, sin duda, trajo conflictos por la tierra. Si bien, los empresarios que fueron consolidando sus haciendas intentaron hacerlo por medios legales, es decir, denuncios y adjudicaciones de tierras ante la Gobernación de Antioquia y compra de mejoras a colonos, al analizar de cerca los expedientes de baldíos, se observa que también hubo algunas acciones de hecho y uso de la violencia en la ocupación de predios.

Mapa 1: Mapa de predios adjudicados en Antioquia, 1926-1936

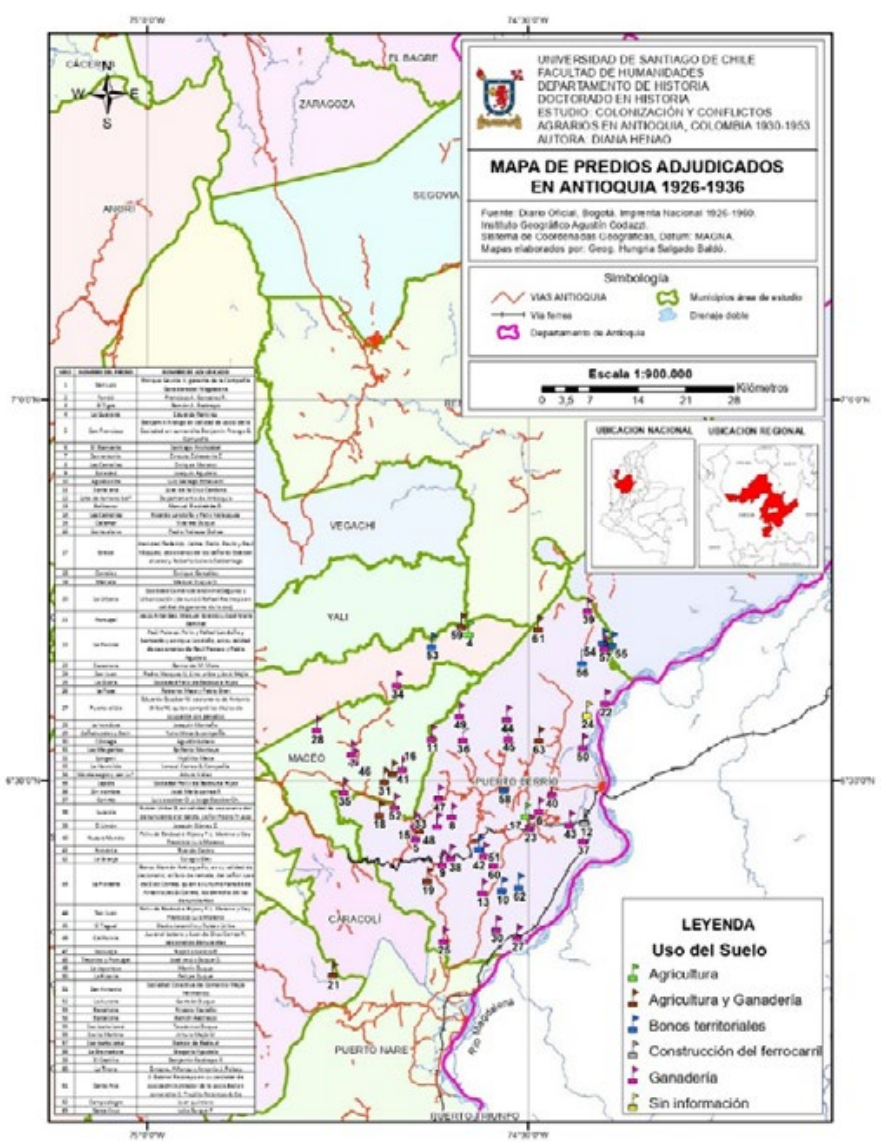

Fuente: Elaboración propia de la autora a partir del Diario Oficial, 1926-1936 


\section{Conflictos entre empresarios de Medellín y la Sociedad AgríCOLA Y DE INMIGRACIÓN}

En el periodo de estudio que abarca este artículo, uno de los actores centrales por el control de las tierras de Puerto Berrío fue la "Sociedad Agrícola y de Inmigración", que, si bien data de 1872, su papel en la disputa por la tierra se dará a partir de la década del veinte del siglo pasado. La ley 63 de 1872 cedió al Estado Soberano de Antioquia 200.000 hectáreas para el fomento de la inmigración y la construcción del ferrocarril de Antioquia. El contrato celebrado entre el Estado Soberano de Antioquia y el ingeniero Francisco Cisneros en 1874, estipulaba que, Cisneros tendría "el derecho exclusivo de construir y explotar un ferrocarril de vía angosta, de moción a vapor, desde el punto denominado "Puerto Berrío" en la margen del río Magdalena, hasta el de "Aguas Claras" en el Distrito de Barbosa, adoptando entre dichos puntos el trazo que fuere más conveniente, a juicio del concesionario"16. Para tal efecto se cedieron 100.000 hectáreas de terreno, de las ya cedidas al Estado en 1872. Estas hectáreas estarían distribuidas a lado y lado de la vía por donde pasaría el ferrocarril y separadas en diez lotes de 10.000 hectáreas cada uno.

Ahora bien, por la ley 36 del 4 de diciembre de 1877, la Asamblea Legislativa del Estado Soberano de Antioquia, cedía a favor de un individuo o una sociedad, las otras 100.000 hectáreas de tierras baldías con el fin de fomentar la inmigración y la agricultura. Esta ley establecía que, para efectos de entrega de las tierras, se haría una licitación pública que estaría vigente durante noventa días. La sociedad que fuera beneficiaria de las tierras debía consignar dentro de sesenta días la suma que estableciera el Estado por el valor de estas, las cuales estarían representadas en bonos territoriales ${ }^{17}$. Quien fuera el adjudicatario de estas tierras, debía formar una Sociedad Agrícola y de Inmigración con un capital de cien mil pesos, sin incluir el valor de las tierras que obtuviera. Además, debía

16 Sociedad Agrícola y de Inmigración, "Compilación de los principales documentos sobre la Sociedad Agrícola y de Inmigración” (Medellín: Imprenta Oficial, 1921), 20.

17 Cuando se tenían bonos territoriales, los mismos debían ser redimidos por tierras baldías, por tanto, quienes obtenían tierras a cambio de estos bonos, debían acogerse a los procedimientos legales para acceder a la adjudicación de tierras. 
empezar trabajos agrícolas dentro de los seis meses siguientes a la fecha de la escritura y de la constitución e incorporación legal de ella.

Es así como se crea la Sociedad Agrícola y de Inmigración, cuyos socios fueron Francisco Cisneros, Francisco de Villa y Jorge Bravo. La sociedad tenía por objeto: "adquirir en propiedad las cien mil hectáreas de tierras baldías de que trata la Ley 36 citada y las cien mil hectáreas de baldíos a que tiene derecho el Sr. Cisneros, como contratista del Ferrocarril de Antioquia, hasta obtener, previas las formalidades legales, la posesión judicial o legal de todas ellas" "18. En consecuencia, esta sociedad quedó a cargo de las 200.000 hectáreas de terreno que iban a entrar en disputa en la década del veinte del siglo pasado.

Además del fomento de la agricultura y la inmigración, la Sociedad también se proponía: a) adquirir en propiedad las minas que se hallaran dentro de sus terrenos; b) promover la inmigración extranjera y del país en los terrenos de su propiedad; c) fundar poblaciones; d) favorecer la industria agrícola fomentando el establecimiento de colonos en sus terrenos; e) exportar por su cuenta productos naturales de sus tierras; y f) favorecer los intereses de la empresa del Ferrocarril de Antioquia cediendo la faja de terreno que pueda ser necesaria para la vía férrea ${ }^{19}$.

Estas labores debían ser cumplidas en el transcurso de diez años. Terminado ese tiempo, los socios podían prorrogar la sociedad, si así lo convenían. No obstante, después de estos primeros diez años, como lo advertía el abogado Joaquín Agudelo, la Sociedad no cumplió con estos objetivos, por tanto, se produjo su disolución. Paralelamente, Francisco Cisneros y el Estado Soberano de Antioquia dieron por terminado el contrato de construcción del ferrocarril, en favor de la inauguración de la República centralizada; así las cien mil hectáreas que el ingeniero aportó a la Sociedad Agrícola y de Inmigración retornaron a la República, por tanto, el capital de la Sociedad quedó en manos de Francisco de Villa y el Estado Soberano de Antioquia.

18 "Escritura de constitución de la Sociedad Agrícola y de Inmigración, 7 de agosto de 1878".

19 "Escritura de constitución de la Sociedad Agrícola y de Inmigración, 7 de agosto de 1878". 
A pesar de estos hechos, Villa y Arango intentaron reconstituir la Sociedad en 1899, con "las mismas bases sobre las que estaba constituida". Sin embargo, después de varios litigios se consideró nula por varias razones. En primer lugar, la Sociedad que se reconstituyó en 1899 no fijó el capital de la Compañía de manera precisa; además, la escritura no se registró dentro de los quince días inmediatos a la fecha de realización ni tampoco un extracto de esta fue publicado en la Gaceta Departamental. Estas formalidades eran exigidas por el Código de Comercio y eran suficientes para que la Sociedad no quedara legalmente constituida. En segundo lugar, la Sociedad Agrícola, no era la dueña de los terrenos en Puerto Berrío, si bien poseía los bonos territoriales, nunca realizó el procedimiento formal que exigía el Ministerio para el denuncio y adjudicación de los predios. En consecuencia, las oposiciones a denuncios de terrenos que empezó a hacer la Sociedad desde la década del veinte eran ineficaces.

Estos estudios y conceptos sobre la Sociedad Agrícola se empezaron a hacer en 1921 y estuvieron a cargo de varios abogados, entre ellos Joaquín Agudelo, quien fue el apoderado de varios empresarios ganaderos que pretendían se les adjudicaran las tierras de Puerto Berrío, con el fin de dedicarlas a la ganadería. Una de las razones que explican los litigios con la Sociedad y los estudios en torno a su constitución, es que justo en este momento, buena parte de la línea férrea estaba construida, por tanto, había una conexión más expedita entre Medellín y el río Magdalena. Si bien, es 1929 el año de terminación definitiva del Ferrocarril, 1920 es una fecha importante, ya que se inaugura la estación El Limón, en donde desembocaría el túnel de la Quiebra, el paso que más preocupó a los directivos de la empresa del Ferrocarril de Antioquia.

En el Archivo Histórico de Antioquia y el Archivo Histórico Judicial de Medellín se encontraron varios de estos expedientes que contienen los conflictos por el acceso y control del territorio por parte de la Sociedad

36 Agrícola y de Inmigración y varios empresarios del centro de Antioquia, que, en su mayoría, a título de ocupantes con ganado y en menor medida de agricultores, accedieron al procedimiento legal para la adjudicación 
de los predios. Lo que tienen en común estos expedientes es que el apoderado fue Joaquín Agudelo, abogado especializado en el ramo de Minas y Baldíos, quien, junto con Clodomiro Ramírez, fue el encargado de los juicios en relación con oposiciones a denuncios de baldíos. Agudelo fue un actor clave en los pleitos con la Agrícola, puesto que, el estudio que realizó sobre la reconstitución de la Sociedad fue fundamental para ganar los litigios en los que participó como apoderado de empresarios antioqueños.

En estos expedientes de baldíos, las oposiciones estuvieron en manos de Juan B. Arango en calidad de presidente y Francisco de Villa como vicepresidente de la Sociedad, no obstante, ambos estuvieron representados por su abogado Isaías Cuartas. Cabe anotar, que los expedientes encontrados no correspondieron exclusivamente a predios ubicados en Puerto Berrío, sino que también hubo pleitos en Yolombó y en Remedios, municipios por donde pasaba la línea del ferrocarril o donde se ubicaban parte de los terrenos que la Sociedad reclamaba como suyos. En el cuadro 1 se enlistan los expedientes de baldíos encontrados en archivos regionales, en los que la Sociedad Agrícola se opuso a los denunciantes de tierras baldías.

Ahora bien, los predios que fueron adjudicados a empresarios y en los cuales se opuso la Sociedad, fueron más de los señalados en el cuadro anterior. Los predios adjudicados por el Ministerio de Industrias fueron treinta y seis. En su mayoría los terrenos estuvieron dedicados a la ganadería y representaron un total de 55.246 hectáreas de terreno, solo en el municipio de Puerto Berrío. En el cuadro número 2 se enlistan las adjudicaciones cuya resolución aparece en el Diario Oficial y en las que la Sociedad Agrícola hizo oposiciones. Como se observa las adjudicaciones estuvieron concentradas en los primeros años de la década del treinta, lo que sin duda elevó el número de adjudicaciones en el periodo que va de 1926 a 1936. A su vez, estos predios fueron adjudicados principalmente a empresarios de Medellín que vieron en la ganadería una opción para diversificar sus actividades económicas. 


\section{Cuadro 1}

Expedientes de baldíos cuyo opositor fue la Sociedad Agrícola y de Inmigración

\begin{tabular}{|c|c|c|c|c|c|}
\hline $\begin{array}{c}\text { Año del } \\
\text { denuncio }\end{array}$ & Denunciante & $\begin{array}{l}\text { Calidad del } \\
\text { solicitante }\end{array}$ & $\begin{array}{l}\text { Ubicación } \\
\text { del predio }\end{array}$ & $\begin{array}{c}\text { Nombre del } \\
\text { predio }\end{array}$ & Hectáreas \\
\hline 1920 & Luciano Villa & $\begin{array}{l}\text { Títulos de } \\
\text { concesión }\end{array}$ & Remedios & Júpiter & 2.500 \\
\hline 1920 & José Pablo Vélez & $\begin{array}{l}\text { Títulos de } \\
\text { concesión }\end{array}$ & Remedios & $\begin{array}{l}\text { Pernanbunco } \\
\text { y Ciénaga del } \\
\text { Encanto }\end{array}$ & 2.500 \\
\hline 1920 & $\begin{array}{l}\text { Antonio Borda } \\
\text { C. }\end{array}$ & $\begin{array}{l}\text { Títulos de } \\
\text { concesión }\end{array}$ & Remedios & Ité & 5.000 \\
\hline 1920 & $\begin{array}{l}\text { Antonio Borda } \\
\text { C. }\end{array}$ & $\begin{array}{l}\text { Títulos de } \\
\text { concesión }\end{array}$ & Remedios & Caño Negro & 5.000 \\
\hline 1920 & Gabriel Ángel & $\begin{array}{l}\text { Títulos de } \\
\text { concesión }\end{array}$ & Remedios & $\begin{array}{l}\text { Río Nuevo o } \\
\text { Zahíno }\end{array}$ & 2.500 \\
\hline 1924 & $\begin{array}{l}\text { Rafael Escobar, } \\
\text { Mauro Her- } \\
\text { nández, Raúl } \\
\text { Hernández }\end{array}$ & $\begin{array}{l}\text { Bonos terri- } \\
\text { toriales }\end{array}$ & Puerto Berrío & El Ejído & 2.500 \\
\hline 1924 & Joaquín Agudelo & $\begin{array}{l}\text { Ocupante } \\
\text { con ganados }\end{array}$ & Puerto Berrío & La Soledad & 800 \\
\hline 1924 & $\begin{array}{l}\text { Severo Velás- } \\
\text { quez }\end{array}$ & $\begin{array}{l}\text { Ocupante } \\
\text { con ganados }\end{array}$ & Puerto Berrío & $\begin{array}{l}\text { Ánimas } \\
\text { y Charco } \\
\text { Negro }\end{array}$ & 700 \\
\hline 1925 & Marco A. López & $\begin{array}{l}\text { Ocupante } \\
\text { con ganados }\end{array}$ & $\begin{array}{l}\text { Puerto Berrío } \\
\text { y Yolombó }\end{array}$ & La Giranda & 350 \\
\hline 1925 & Marco A. López & $\begin{array}{l}\text { Ocupante } \\
\text { con ganados }\end{array}$ & Puerto Berrío & La Helena & 200 \\
\hline 1925 & $\begin{array}{l}\text { Teodosio Mo- } \\
\text { lina }\end{array}$ & $\begin{array}{l}\text { Ocupante } \\
\text { con ganados }\end{array}$ & Puerto Berrío & Pajuí & 800 \\
\hline 1925 & Francisco Marín & $\begin{array}{l}\text { Ocupante } \\
\text { con ganados }\end{array}$ & Puerto Berrío & San Carlos & 800 \\
\hline 1928 & $\begin{array}{l}\text { Aquileo Mon- } \\
\text { toya }\end{array}$ & $\begin{array}{l}\text { Bonos terri- } \\
\text { toriales }\end{array}$ & Puerto Berrío & La Calera & 2.500 \\
\hline 1929 & $\begin{array}{l}\text { Marco Tulio } \\
\text { Ceballos, Teó- } \\
\text { dulo Saldarriaga, } \\
\text { Tobías Marín } \\
\end{array}$ & $\begin{array}{l}\text { Ocupante } \\
\text { con ganados }\end{array}$ & Puerto Berrío & Ejido & 2.500 \\
\hline $\begin{array}{l}\text { Total hec- } \\
\text { táreas en } \\
\text { litigio }\end{array}$ & & & & & 28.658 \\
\hline
\end{tabular}

Fuente: Archivo Histórico de Antioquia (AHA), Secretaría de Hacienda, Minas y Baldíos, Puerto Berrío, Yolombó.

Archivo Histórico Judicial de Medellín (AHJM), "Juicio contra la declaratoria de un terreno baldío”, Documentos. 8736 y 8752,1920 


\section{Cuadro 2}

Adjudicaciones cuyo opositor fue la Sociedad Agrícola y de Inmigración

\begin{tabular}{|c|c|c|c|c|}
\hline $\begin{array}{l}\text { Año de ad- } \\
\text { judicación }\end{array}$ & $\begin{array}{l}\text { Nombre del } \\
\text { predio }\end{array}$ & Hectáreas & Adjudicatarios & $\begin{array}{l}\text { Calidad del } \\
\text { solicitante }\end{array}$ \\
\hline 1931 & Aguabonita & 2.500 & Luis Gallego Echeverri & $\begin{array}{l}\text { Bonos terri- } \\
\text { toriales }\end{array}$ \\
\hline 1931 & Santa Ana & 672 & Juan de la Cruz Cardona & Ganadero \\
\hline 1932 & Balkanes & 2.498 & Manuel Piedrahita D. & Ganadero \\
\hline 1933 & Calamar & 1.562 & Vicente Duque & Ganadero \\
\hline 1933 & Grecia & 716 & $\begin{array}{l}\text { Esteban Álvarez y Roberto } \\
\text { Botero Saldarriaga }\end{array}$ & Cultivador \\
\hline 1933 & Corrales & 223 & Enrique González & $\begin{array}{l}\text { Ganadero y } \\
\text { cultivador }\end{array}$ \\
\hline 1933 & Mariela & 453 & Manuel Duque D. & $\begin{array}{l}\text { Ganadero y } \\
\text { cultivador }\end{array}$ \\
\hline 1933 & La Florida & 2.500 & $\begin{array}{l}\text { Raúl Paneso Félix y Rafael } \\
\text { Londoño y Bernardo y Enrique } \\
\text { Londoño }\end{array}$ & Ganadero \\
\hline 1933 & Casamora & 2.485 & Bernardo M. Mora & Ganadero \\
\hline 1933 & San Juan & 2.499 & $\begin{array}{l}\text { Pedro Vásquez U. Lino Uribe y } \\
\text { José Mejía }\end{array}$ & $\begin{array}{l}\text { Sin informa- } \\
\text { ción }\end{array}$ \\
\hline 1933 & La Hondura & 531 & Joaquín Montaño & Ganadero \\
\hline 1933 & Las Margaritas & 2.224 & Epifanio Montoya & $\begin{array}{l}\text { Ganadero y } \\
\text { cultivador }\end{array}$ \\
\hline 1933 & La Hermilda & 703 & Ismael Correa \& Compañía & Ganadero \\
\hline 1934 & Córcega & 2.476 & Agustín Botero & Ganadero \\
\hline 1934 & Corinto & 270 & $\begin{array}{l}\text { Luis Escobar O. y Jorge Esco- } \\
\text { bar Ch. }\end{array}$ & Ganadero \\
\hline 1934 & Lucania & 736 & $\begin{array}{l}\text { Rubén Uribe } \mathrm{D} \text {, en calidad de } \\
\text { cesionario del denunciante del } \\
\text { baldío, señor Pedro Trucco }\end{array}$ & Ganadero \\
\hline 1934 & Nuevo Mundo & 2.049 & $\begin{array}{l}\text { Felix de Bedout e Hijos y F.L. } \\
\text { Moreno y Ca y Francisco Luis } \\
\text { Moreno }\end{array}$ & Ganadero \\
\hline 1933 & Armenia & 1.149 & Ricardo Castro & Ganadero \\
\hline 1934 & La Granja & 443 & Eulogio Díez & Ganadero \\
\hline 1934 & La Floresta & 765 & Banco Alemán Antioqueño & Ganadero \\
\hline 1934 & San Juan & 1.756 & $\begin{array}{l}\text { Felix de Bedout e Hijos y F.L. } \\
\text { Moreno y Ca y Francisco Luis } \\
\text { Moreno }\end{array}$ & Ganadero \\
\hline 1933 & El Tagual & 409 & Eladio Jaramillo y Rubén Uribe & Ganadero \\
\hline
\end{tabular}




\begin{tabular}{|c|c|c|c|c|}
\hline $\begin{array}{l}\text { Año de ad- } \\
\text { judicación }\end{array}$ & $\begin{array}{c}\text { Nombre del } \\
\text { predio }\end{array}$ & Hectáreas & Adjudicatarios & $\begin{array}{c}\text { Calidad del } \\
\text { solicitante }\end{array}$ \\
\hline 1934 & California & 2.444 & $\begin{array}{l}\text { Juvenal Botero y Juan de Dios } \\
\text { Correa R. }\end{array}$ & Ganadero \\
\hline 1934 & Noruega & 2.473 & Rogelio Botero B. & Ganadero \\
\hline 1934 & $\begin{array}{l}\text { Tesorito y } \\
\text { Portugal }\end{array}$ & 602 & José Jesús Duque D. & $\begin{array}{l}\text { Ganadero y } \\
\text { cultivador }\end{array}$ \\
\hline 1934 & La Japonesa & 896 & Martín Duque & Ganadero \\
\hline 1934 & La Pizarra & 2.158 & Felipe Duque & Ganadero \\
\hline 1934 & San Antonio & 564 & $\begin{array}{l}\text { Sociedad Colectiva de Comer- } \\
\text { cio Mejía Hermanos }\end{array}$ & $\begin{array}{l}\text { Bonos terri- } \\
\text { toriales }\end{array}$ \\
\hline 1934 & La Aurora & 2.500 & Germán Duque & Ganadero \\
\hline 1935 & Barcelona & 1.965 & Nicasio Castaño & $\begin{array}{l}\text { Bonos terri- } \\
\text { toriales }\end{array}$ \\
\hline 1935 & Barcelona & 2.073 & Ramón Restrepo & $\begin{array}{l}\text { Bonos terri- } \\
\text { toriales }\end{array}$ \\
\hline 1935 & San Bartolomé & 2.052 & Teodorico Duque & $\begin{array}{l}\text { Bonos terri- } \\
\text { toriales }\end{array}$ \\
\hline 1935 & Santa Martina & 1.722 & Arturo Mejía M. & $\begin{array}{l}\text { Bonos terri- } \\
\text { toriales }\end{array}$ \\
\hline 1935 & La Bramadora & 2.500 & Gregorio Agudelo & $\begin{array}{l}\text { Bonos terri- } \\
\text { toriales }\end{array}$ \\
\hline 1936 & Campoalegre & 2.500 & Juan Quintero & $\begin{array}{l}\text { Bonos terri- } \\
\text { toriales }\end{array}$ \\
\hline 1936 & Santa Cruz & 1.178 & Julio Duque F. & $\begin{array}{l}\text { Ganadero y } \\
\text { cultivador }\end{array}$ \\
\hline $\begin{array}{l}\text { Total ha } \\
\text { adjudicadas }\end{array}$ & & 5.5246 & & \\
\hline
\end{tabular}

Fuente: Diario oficial, Imprenta Nacional, Bogotá: 1926-1960

Aunque en los pleitos que inmiscuyeron a la Agrícola no quedó registrado uso de la violencia, no puede afirmarse que la conformación de estas haciendas en el Magdalena Medio estuvo exenta de episodios violentos. Algunos de los trabajos más recientes sobre historia de la ganadería, en un intento revisionista de la historiografía más tradicional tienden a invertir la narrativa dominante. Así, se pasa de una historia que presenta una imagen negativa de la ganadería, en donde esta actividad económica es irracional y solamente funciona en el latifundio, a una historia empresarial que se centra más en algunos sujetos de la élite, siguiendo sus carreras empresariales y sus intereses en el comercio y 
la industria. En consecuencia, hay un giro de una historia "irracional" a una "racional". Uno de los trabajos que ha hecho aportes importantes sobre la ganadería en Puerto Berrío ${ }^{20}$, cae en esta última visión, desconociendo que la conformación de la hacienda en la subregión del Magdalena Medio también fue conflictiva y violenta. Así al analizar este proceso de consolidación de la hacienda ganadera en Puerto Berrío, se considera un punto intermedio entre ambas visiones, tal como ha señalado Shawn van Ausdal, el legado de la ganadería "[...]no es tan negativo como a menudo se ha imaginado, pero es también un error pasar por alto las formas en que la historia de la ganadería está atada al poder y a la inequidad"21.

Por otra parte, en los pleitos de la Sociedad Agrícola y los empresarios de Medellín, también hubo participación de colonos, quienes tenían sus mejoras en los predios en disputa. En consecuencia, en este proceso no solamente se enfrentaron dos grupos de poder antioqueños, los empresarios agrícolas de Medellín y la Sociedad Agrícola, cuyos socios fueron también hombres influyentes de la sociedad paisa. Si bien, no se encontraron muchos registros que involucren a colonos en este proceso de adjudicación de las tierras de la Agrícola, el caso de la hacienda La Aurora (2.500 ha), adjudicada a Germán Duque en 1934, es ilustrativo.

A partir de 1924, doce colonos, cuyo representante fue Antonio Ceballos, también colono, hicieron valer su derecho a la tierra. En la denuncia enviada al juez municipal de Puerto Berrío, los colonos afirmaban que desde hacía cinco años que estaban mejorando los terrenos como colonos y cultivadores, con sus casas de habitación y con cultivos permanentes. Estos lotes que reclamaban como suyos estaban comprendidos dentro del lote general que había denunciado Duque, denominado La Aurora ${ }^{22}$. Los campesinos interpusieron la querella,

20 José Roberto Álvarez Múnera, Mercado, ganado y territorio: Haciendas y hacendados en el Oriente y el Magdalena Medio antioqueños (1920-1960) (Medellín: Universidad de Antioquia, 2016).

21 Shawn Ausdal, "Ni calamidad no panacea: Una reflexión en torno a la historiografía de la ganadería colombiana", en El poder de la carne. Historias de ganaderías en la primera mitad del siglo XX en Colombia, ed. Alberto Florez-Malagón (Bogotá: Pontificia Universidad Javeriana, 2012), 28.

22 Los colonos que hicieron la denuncia fueron: Felipe López, terreno Agua Bonita, extensión de 100 almudes; Antonio Taborda, terreno Las Agüitas de 80 almudes; Manuel Antonio Ceballos, terreno El Encanto; Manuel Rodríguez, un terreno de 18 almudes; Juan Galvis, terreno El Líbano de 30 almudes; Luis Rúa terreno el Alto de la Alegría de 35 almudes; Obdulio Laverde, terreno El Repecho 
porque en el denuncio que el empresario hizo no se respetaban sus terrenos y mejoras, tal como lo estipulaba la ley. Los colonos afirmaban que, si bien Duque reconocía que dentro del terreno que denunciaba sí había algunos colonos establecidos con anterioridad al denuncio, no reconocía la validez de todas las oposiciones elevadas al juez municipal. Según Duque no todos los opositores tenían derecho, es decir, que el número de colonos en los terrenos que él denunciaba era menor, a lo que se sumaba que, según el empresario, la extensión de terreno que decían poseer los colonos era menor.

La adjudicación de La Aurora otorgada a Germán Duque en 1934 no nos da indicios de si se respetaron o no los terrenos de los colonos establecidos, aunque es probable que los colonos decidieran desplazarse para otros terrenos a mejorar tierra o se quedaran en los terrenos alrededor de la finca y sirvieran como mano de obra para este empresario agrícola. A su vez, este caso es ilustrativo no solo de las formas de consolidación de fincas ganaderas, sino también de la concentración de la tierra en pocas manos. En 1934 también se adjudicó a los hermanos de Duque, Felipe y Martín, los predios La Pizarra de 2.158 hectáreas y La Japonesa de 896 hectáreas, respectivamente ${ }^{23}$. De esta forma quedó en manos de la familia Duque un total de 5.554 hectáreas dedicadas a la ganadería, en una de las zonas más fértiles del departamento.

Así, los conflictos en esta subregión también se expresaron de arriba hacia abajo, involucrando empresarios agrícolas, ganaderos y colonos sin títulos formales de tierra. En consecuencia, algunos de los conflictos del Magdalena Medio se dieron de manera similar a como se dio la segunda fase de colonización de baldíos en otras regiones del país, en donde se dio la apropiación del trabajo campesino y la usurpación de sus tierras, paralelamente se usaron mecanismos legales para la adquisición de predios. A propósito de este último mecanismo, en las fuentes revisadas, cuando el pequeño cultivador hacía los denuncios de tierras públicas y Ángel Suárez un terreno de 10 almudes. AHA, Secretaría de Hacienda, Minas y Baldíos, Tomo 5126, Carpeta 1, 1924, f. 1-13.

23 AHA, Secretaría de Hacienda, Minas y Baldíos, Tomo 5126, Carpeta 1, 1924, f. 1-13. Diario Oficial, Bogotá, 1934. 
ya la Gobernación del departamento le había otorgado la adjudicación provisional, al momento de la diligencia de entrega aparecían las oposiciones de los empresarios agrícolas, quienes por lo general afirmaban que los predios denunciados por el campesinado estaban dentro de sus fincas, o aseguraban que los colonos denunciantes eran sus arrendatarios. Estas oposiciones, en más de una ocasión, fueron favorables a los empresarios agrícolas y sobre todo a los gamonales, quienes además de los recursos económicos para llevar a cabo los denuncios, contaban con el favor de las autoridades locales, que terminaban aceptando las oposiciones. En consecuencia, los campesinos terminaban renunciando a los denuncios de tierras y quedaban susceptibles a la evicción.

Los pleitos en los que la Sociedad Agrícola y de Inmigración participó como opositora llegaron a su fin en la década del treinta, cuando el abogado Joaquín Agudelo ya había demostrado ampliamente la imposibilidad de la Sociedad de acceder a los terrenos. En este conflicto los ganadores fueron los empresarios de Medellín que se hicieron a un importante número de hectáreas en las fértiles tierras del Magdalena Medio, lo que sin duda les permitió diversificar sus actividades económicas, por medio de una industria que empezó a cobrar importancia en la región a partir de la década del treinta. No obstante, en la subregión del Magdalena Medio, estos no serán los únicos actores involucrados en los procesos de colonización. La dinámica de adjudicación de tierras públicas va a continuar su ritmo hasta 1946, año en el cual los procedimientos formales para el denuncio de baldíos se modificarán. La Ley 97 de ese año, si bien, seguía estipulando que debía enviarse un memorial dirigido al Gobernador, a la par se debía adjuntar un plano del predio denunciado y realizar una inspección ocular; esto sin duda estuvo en detrimento del campesinado, que ahora debía contar con mayores recursos para elevar los denuncios de predios. Durante el ciclo de protesta campesina que se analiza en este artículo (1926-1947) no solo quedaron registrados estos conflictos agrícolas entre las mismas élites del centro de Antioquia, también hubo conflictos que involucraron al campesinado entre sí y en donde el uso de la violencia se hizo presente. 


\section{Dinamismo de la conflictividad social en la Frontera ANTIOQUEÑA}

El panorama general de los procesos de ocupación del Magdalena Medio muestra una amplia diversidad de conflictos en los que los colonos son actores centrales. En primer lugar, están los que, si bien, se expresan de arriba hacia abajo, no necesariamente involucraron a empresarios agrícolas de Medellín, sino que más bien correspondieron a conflictos entre colonos y pequeños o medianos propietarios lugareños de los municipios. Estos propietarios algunas veces eran vecinos notables, gamonales o jefes políticos, siendo estos últimos a quienes los campesinos acusaban de ser los principales usurpadores de su trabajo y tierras y de usar mecanismos violentos de despojo como la destrucción de cultivos, cercos y casas de habitación. Sin embargo, el uso de la violencia no es exclusivo de los de arriba; los colonos, además de formas de resistencia, como por ejemplo la ocupación de terrenos de los cuales habían sido expulsados, también harían uso de la fuerza para defenderse de los despojadores y de quienes querían apropiarse de su trabajo, incluidos otros colonos sin tierra.

Con respecto a los enfrentamientos entre propietarios lugareños y pequeños colonos, uno de los casos que mejor permite ilustrar este tipo de conflictos, es en el que se enfrentaron Ignacio Uribe y su hijo Mario, con algunos colonos del corregimiento de San José de Providencia, que correspondió en un primer momento a Yolombó y posteriormente al municipio de Maceo. De acuerdo con algunos documentos de la década del treinta Ignacio Uribe poseía cierto grado de notabilidad dentro de la zona en donde se ubicaba su finca. Cabe anotar aquí que uno de los primeros documentos en donde se menciona a Ignacio Uribe, hace referencia a un lote de terreno adjudicado por la "Junta Agraria" de Puerto Berrío, organización que empezó a adjudicar baldíos en Maceo desde 1918 aproximadamente. En este documento, redactado por el registrador de Instrumentos Públicos, se observa que en 1919 Uribe obtuvo un terreno, ubicado en San José cerca de la estación del ferrocarril del mismo nombre. No obstante, el registrador afirmaba que estas adjudicaciones no podían ser legales, ya que era el Ministerio Nacional el encargado de otorgarlas oficialmente y no una junta conformada 
por algunos vecinos y autoridades locales. En consecuencia, quienes obtuvieron algún predio gracias a la Junta no se acogieron al procedimiento que la ley establecía, lo que derivó en conflictos con colonos ${ }^{24}$.

Ya para 1935 se empiezan a observar conflictos entre Ignacio Uribe y su hijo Mario con varios colonos. En ese año quien le interpone una querella es el colono Antonio Arias que acusaba a los Uribe de estar perturbándolo en su terreno, a su vez, Ignacio y Mario sostenían que Arias estaba ocupando los predios de la finca de San José con ganado. Por causa de las perturbaciones, el alcalde decidió multar a Ignacio Uribe con 200 pesos; en arremetida a la querella presentada por el colono, Mario Uribe decidió presentarse en el terreno de Arias en donde "[...] hizo a este cinco disparos de revólver que no hicieron blanco”. Frente a este hecho, el juzgado decidió que Arias y Uribe debían ser multados para que "guardasen la paz". La respuesta de Mario Uribe resultó de nuevo violenta y después de la decisión del juzgado, tumbó los cercos del predio de Arias por lo que el ganado se "regó por la carrilera y predios vecinos" 25 . Los Uribe sostenían que se valían de estas acciones de hecho porque desde 1927 no solo Antonio Arias, sino "otros muchos" transitaban y derribaban los cercos de su propiedad. Arias por su parte, afirmaba que los dueños de la finca San José no acataban "las providencias judiciales y administrativas", y que además de los tiros y la destrucción de cercos, Uribe había enviado a dos peones suyos a sacar leñas de sus predios ${ }^{26}$.

A finales de ese mismo año, la alcaldía informaba que había hecho la entrega del lote El Canelo a Ignacio Uribe. En este denuncio se opusieron algunos colonos, sin embargo, no se presentaron el día de la entrega del lote, ya que eran considerados como "perturbadores". Por esta razón, el alcalde decidió dejar cuatro agentes de policía vigilando, durante dos días, el terreno en caso de que los colonos quisieran ocuparlo nuevamente. Cuando los agentes se fueron, los colonos en un acto de resistencia regresaron a los predios en donde tenían sus cultivos, aunque este hecho supusiera una multa. Estas multas se hicieron efectivas e

24 AHA, Secretaría de Gobierno, Gobierno Municipios, Tomo 435, Yolombó, 1935, f. 451.

25 AHA, Secretaría de Gobierno, Gobierno Municipios, Tomo 435, Yolombó, 1935, f. 466.

26 AHA, Secretaría de Gobierno, Gobierno Municipios, Tomo 435, Yolombó, 1935, f. 468. 
incluso uno de los colonos que regresó a El Canelo fue encarcelado. Ante esta situación el alcalde afirmaba que, debido a las ocupaciones de los colonos, debían instalarse en el predio por lo menos dos policías departamentales "a fin de que no continúe esta burla, pues nos hallamos en un círculo vicioso" 27 ya que, cada vez que el terreno quedaba libre de agentes de policía, los colonos regresaban a ocuparlo.

Lo que queda claro en este caso es que las autoridades del corregimiento de San José actuaban de acuerdo con los intereses de la familia Uribe. No solo los fallos del juzgado municipal los favorecían, sino que, incluso cuando Mario hizo los disparos en el terreno de Arias, no tuvo que cumplir ningún tipo de condena en la cárcel. A su vez, la presencia de agentes de policía en los predios de los Uribe refuerza esta idea. Sin embargo, los colonos en un acto de resistencia ocupaban nuevamente los terrenos después de ser expulsados, lo que significaba que podían ser multados e incluso encarcelados.

Empero, los conflictos de los Uribe con los colonos se van a extender hasta la década del cuarenta. Ahora, los predios de la familia formaban parte del municipio de Maceo, las disputas por la tierra tendrán su punto más álgido en 1946, cuando José de Jesús Henao es acusado por daños a la propiedad. Sin embargo, desde 1932 ya se tienen noticias de estas disputas entre los Uribe y los Henao, cuando un visitador administrativo informó sobre unos sumarios en donde el acusado era José de Jesús. El conflicto escaló cuando los Uribe enviaron a unos peones de su finca a destruir los cercos que dividían las dos propiedades, arguyendo que las mejoras de los Henao estaban dentro de su propiedad, San José. Los Henao en defensa de su tierra y trabajo y ante la pasividad de las autoridades locales, "armados de escopetas... y en actitud amenazante", ordenaron a los peones de Uribe que no continuaran el retiro de los cercos. Este hecho, se tradujo en una orden de encarcelamiento a José. Sin embargo, el día en que los agentes de policía llegaron a su casa para cumplir la orden de arresto, José no estaba, así que arbitrariamente los policías encarcelaron a uno de los sobrinos, Juan Bautista, quien afirmó “...me llevaron para San José y me condujeron a la cárcel donde

27 AHA, Secretaría de Gobierno, Gobierno Municipios, Tomo 435, Yolombó, 1935, f. 504. 
estuve detenido veinticuatro horas y al momento de ponerme (sic) en libertad me dijo el inspector que tenía que pagar una multa y que si no me mandaba para las colonias" 28 .

En este contexto, el memorial que redactó Felicidad Henao al gobernador de Antioquia es clave para comprender el conflicto. Cuenta Felicidad que en 1914 ella y su hermano José llegaron a San José de Providencia junto con sus padres en calidad de colonos, por tanto, llevaban más de tres décadas en la región, trabajando la tierra. El conflicto surgió cuando Ignacio Uribe compró unas mejoras a Elías Isaza, quedando englobadas dentro de la escritura las mejoras de los Henao y de otros colonos entre ellos Marcial Gutiérrez y Lisandro Sierra. Es por esta razón que los Uribe intentaron expulsarlos por varios medios, primero interponiendo querellas contra ellos o denuncios criminales falsos, luego destruyendo los cercos y finalmente decomisándoles maderas que Uribe argüía eran sacadas de su propiedad. En este memorial, Felicidad también advertía sobre las querellas que habían interpuesto frente al juzgado municipal, pero estas no se hacían valer porque la policía actuaba en favor de los Uribe. $^{29}$ Por esta razón, los colonos acudieron al gobierno departamental e incluso al nacional, por medio de un telegrama enviado al Procurador General.

Este telegrama revela que en uno de los encuentros entre Mario Uribe y José Henao, el primero continuó destruyendo los cercos, las sementeras y la casa de habitación y José en "legítima defensa" disparó a Alfredo Uribe, otro hijo de Ignacio, quien resultó herido y murió a los dos días. Henao quedó detenido y Mario Uribe continuó haciendo uso de la fuerza para despojar a los Henao de sus mejoras.

Ante estos hechos, el Procurador de la Nación, solicitó al gobernador realizar una comisión para investigar lo ocurrido en el corregimiento de San José. El alcalde de Maceo viajó a San José y la evaluación que hizo fue que este tipo de hechos se daban porque las autoridades actuaban a favor de unos pocos habitantes del lugar. Así el alcalde calificaba al

29 AHA, Secretaría de Gobierno, Gobierno Municipios, Tomo 521, Maceo, 1946, f. 85. 
corregidor de San José como un "hombre de carácter impulsivo, no es querido ni aceptado generalmente por los habitantes de ese corregimiento, a excepción de algunas personas interesadas en que él conserve su puesto" 30 . El alcalde de Maceo consideraba que la parcialidad del funcionario y sus abusos de autoridad habían sido la causa principal del homicidio de Alfredo Uribe. Ejemplo de ello fue el decomiso de un arma a José de Jesús Henao, la cual tenía debidamente registrada.

En resumen, lo que quedaba demostrado es que la parcialidad y poca intervención de las autoridades locales hizo que el conflicto escalara. Incluso Felicidad Henao acudió a los poderes regionales y nacionales pidiendo algún tipo de intervención, ya que las querellas interpuestas a nivel local no habían logrado dar solución al problema. Sin embargo, estas otras instancias a las que acude la colona tampoco dieron ningún tipo de resolución:

"Me permito manifestarle que por el momento no es posible enviar un visitador, como son sus deseos; pero en relación con el caso que a usted interesa, le transcribo, para su conocimiento la comunicación que este despacho ha dirigido al señor Alcalde de ese lugar: Ante el señor Gobernador del Departamento ha expuesto la señora Felicidad Henao H. que contra ella o su hermano José de Jesús existen en esa Alcaldía unos sumarios que les ha hecho iniciar el señor Mario Uribe Uribe. Afirma la mencionada señora que tales expedientes se encuentran demorados en su tramitación y perfección con grave perjuicio para sus intereses. Si el caso fuere verdad, me permito encarecerle el pronto despacho de tales procesos e informarme al respecto" 31 .

A partir del análisis de este caso se observa que hay unos conflictos que exceden los medios legales, por tanto, la violencia se vuelve un mecanismo relevante para intentar resolverlos, dada la incapacidad del aparato judicial de dar soluciones rápidas y por la inclinación de las autoridades locales a defender los intereses de familias que podían ejercer poder dentro de las localidades, en este caso en San José. Parale-

30 AHA, Secretaría de Gobierno, Gobierno Municipios, Tomo 521, Maceo, 1946, f. 103.

31 AHA, Secretaría de Gobierno, Gobierno Municipios, Tomo 521, Maceo, 1946, f. 103. 
lamente, se pueden distinguir formas de resistencia, en las que prevalecen las ocupaciones de terrenos que otros consideraban privados y el uso de los sistemas legales por parte de los colonos. Estos conflictos se dan lejos de los cascos urbanos de los municipios, en los corregimientos y veredas en donde hay una configuración de los territorios y una construcción de redes de poder local particulares, en donde los gamonales o jefes políticos manejan a las autoridades y el aparato legal a su favor.

Ahora bien, de manera paralela a estos conflictos entre jefes políticos o gamonales y campesinos, también hay expresiones de violencia de manera horizontal, es decir, también se registraron enfrentamientos entre los mismos colonos por el control de la tierra. En algunas ocasiones acudieron a las vías legales para tratar de solucionar las controversias al momento del denuncio de baldíos, pero cuando no pudieron resolverse por este medio, los colonos optaron por las vías de hecho.

Un caso en el que colonos tuvieron disputas por la tierra fue el de Ramón Vahos, quien solicitó en adjudicación un terreno llamado "Bracitos" en el corregimiento de Virginias en Puerto Berrío. Al momento de la diligencia de entrega hubo oposiciones de seis colonos que llevaban cuatro años ocupando los terrenos e incluso tenían casas de habitación. Vahos afirmaba que su padre Juan había llegado hacía varios años en calidad de colono, allí trabajó la tierra y el Ministerio le adjudicó un pedazo de terreno; ahora él realizaba el mismo procedimiento para convertirse en propietario. Añadía Vahos que los colonos que se oponían al denuncio en realidad eran sus agregados y por este motivo llevó tres testigos para que dieran fe de esto. Los colonos por su parte negaban cualquier tipo de vínculo contractual con el colono Vahos y decían tener plantadas 43 hectáreas, por tanto, debían ser respetadas y excluidas de la adjudicación. En este tipo de controversias, normalmente la Secretaría de Hacienda pedía la realización de una inspección ocular; particularmente en este caso se buscaba establecer el número de hectáreas plantadas por Vahos y por los colonos. Según la inspección 
Vahos tenía 40 hectáreas mejoradas con pastos y las segundas 14 hectáreas plantadas con maíz, caña, piña y plátano ${ }^{32}$.

Este tipo de conflictos al momento de realizar los denuncios fueron comunes. Si bien, de la lectura del expediente se desprende que Vahos tenía un poco más de recursos que los seis colonos opositores (esto seguramente por llevar más años en el terreno que los otros) no podemos afirmar que Vahos fuera un empresario agrícola o hacendado. El mismo Vahos afirmó que llegó a Virginias en calidad de colono. Algunos de los campesinos que se oponían a las adjudicaciones de otros, en varias ocasiones sí tuvieron algún tipo de relación contractual con el denunciante del terreno. Sin embargo, y de manera similar a como se dio en las haciendas de Cundinamarca, los campesinos desconocieron estas relaciones y optaron por reclamar la tierra como suya; para ello se valieron de testigos que reforzaran sus declaraciones, como en este caso, en donde los seis colonos llevaron a personas para que testificaran a su favor. No se sabe muy bien qué ocurrió entre Vahos y los colonos, parece ser que se respetó una porción del terreno que los colonos decían poseer, aunque no toda la que habían declarado en principio. En este caso no quedó registrado el uso de la violencia entre los colonos, sino que se optó por los procedimientos legales para el acceso a la tierra.

Ahora bien, de los casos encontrados dentro de los expedientes de baldíos que registraron violencia horizontal, fueron los que implicaron disputas por los límites. Dentro de estos casos se encuentra el de Emilio Taborda, vecino de Yolombó, quien denunció un lote de terreno de 20 hectáreas. A tal denuncio se opuso María de Jesús Castrillón, quien, en su calidad de pequeña cultivadora, afirmó que el lote denunciado estaba dentro de su propiedad y que su marido hizo presencia en el lote hasta el día de su muerte "acaecida en esta población de una manera trágica y por motivos de la misma posesión de estos terrenos". Los mecanismos de despojo usados por Taborda implicaron, al igual que los usados por empresarios agrícolas y gamonales, destrucción de cultivos, echando ganado a las sementeras para dañarlas, y particularmente en este caso,

32 AHA, Secretaría de Hacienda, Minas y Baldíos, Puerto Berrío, Caja 5125, Carpeta 2, f. 221-267. 
el asesinato del colono usurpado. María Castrillón explica cómo fue la muerte de su marido:

“Taborda empezó a arrebatarle un lote a cuyo efecto penetró a él y se dedicó a hacer rocerías a arrojar ganados a él y a hacerse dueño por medio del uso... como mi esposo le estorbara aquellas labores y se dedicara a ejecutar actos de dominio más visibles en el lote usurpado, Taborda se vino con una acción sumaria de Policía contra Ibarra valiéndose de testimonios insanos, acción que por fortuna le fue adversa; pero aquí fue Troya. Indignado Taborda por no haber obtenido un éxito completo llevó a cavo (sic) viejas maquinaciones que habían forjado ya en sus sentimientos fantásticos y sabido el desenlace de la querella, cuando momentos antes le reclamaba a la alcaldía de Yolombó y se disponían mandar un agente a la finca por Ibarra; Taborda determinó salir por un camino distinto por no había transitado jamás y fue directamente a dar muerte de la manera más villana"33.

Este último caso nos presenta el uso de la violencia por parte de los sectores populares, con el fin de intentar dar resolución a sus propios conflictos. Por tanto, la violencia no es un mecanismo exclusivo de los de arriba, los sectores populares irrumpieron de manera violenta en el escenario social. ${ }^{34}$ Asimismo, los sujetos populares se manifestaron violentamente frente a los despojos perpetrados no solamente desde arriba, sino también por otros colonos que querían sacarlos de sus mejoras. Las acciones violentas que se desplegaron en este ciclo fueron la destrucción e incendio de casas de habitación, la destrucción de cultivos y en menor medida el asesinato.

Los casos arriba descritos, si bien no son la mayoría dentro del fondo de Minas y Baldíos, si ilustran bien otro tipo de conflictividad horizontal, mostrando que esta no se da exclusivamente entre las élites, como es el caso de la Sociedad Agrícola y de Inmigración y otros empresarios de Medellín, conflictos que aparecen de manera más reiterada. Los casos seleccionados atienden no solo a que sobre ellos se encontraron

33 AHA, Secretaría de Hacienda, Minas y Baldíos, Yolombó, Caja 5134, Carpeta 3, f. 114.

34 Igor Goicovic, "Consideraciones teóricas sobre la violencia social en Chile (1850-1930)", Última Década No. 21 (2005): 121-45. 
expedientes con un mayor volumen de información dentro del fondo, sino que también se encuentran referencias de estos en el fondo de Gobierno Municipios, lo que permite ver un panorama más amplio con respecto a la conflictividad agraria de la zona del Magdalena Medio. Asimismo, revisar estos otros casos permite observar la diversidad de actores que se involucran en la dinámica de ocupación de las fronteras agrícolas, poniendo de manifiesto que dentro del grupo de colonos hay también diferencias socioeconómicas. Hay unos colonos con más recursos y que llevaban instalados durante un mayor número de años en la zona y otros que llevaban poco tiempo habitando la región, en algunas ocasiones estos van a entrar en contradicción, como fue el caso del colono Vahos arriba descrito. Ahora bien, dentro del fondo también se puede identificar el grupo de colonos más pobres, quienes aparecen ya no por medio de expedientes de denuncio de tierras, sino a través de memoriales que redactaban en grupo con reclamaciones a la Gobernación de Antioquia, para hacer valer sus derechos sobre los territorios que estaban ocupando y mejorando desde hacía varios años.

\section{Conclusiones}

Las luchas por la tierra del campesinado que ocupó la frontera antioqueña se enmarcaron en las movilizaciones campesinas que se dieron con fuerza en América Latina tras la crisis del 29. Esta irrupción del campesinado se dio a la par de los cambios en las relaciones agrarias. A pesar de los auges exportadores, las economías nacionales no se habían integrado y el escenario rural continuaba dominado por altos índices de concentración de la tierra. En este contexto, los campesinos fueron agentes importantes de cambio en sus territorios, no solo por sus desplazamientos hacia la frontera agrícola, sino también por la importancia de sus movilizaciones, algunas de las cuales se tradujeron en la lucha abierta entre el campesinado y los empresarios agrícolas.

De esta forma los colonos antioqueños participaron de estos procesos, que particularmente en el caso de Colombia iniciaron en 1926 principalmente en las zonas centrales del país, en donde el sistema hacendatario había sobrevivido casi intacto hasta ese momento. La historiografía colombiana se ha centrado en el estudio de estos campesinos 
que fueron "más políticos" en detrimento de otras zonas en donde fueron "más conservadores". No obstante, a nuestro juicio el estudio de las relaciones agrarias en las zonas en donde el campesinado no tuvo las mismas formas de organización que en las zonas centrales es fundamental para comprender los procesos venideros, particularmente, la manera en la que La Violencia irrumpió a finales de la década del cuarenta. Asimismo, analizar las dinámicas del proceso de colonización hacia subregiones fronterizas de Antioquia, permite destacar que aquí los colonos se abocaron a la lucha por la tierra, sin pasar por las demandas que apuntaban a la modificación de los sistemas de trabajo, como fue el caso de Cundinamarca y Tolima. Esto probablemente se dio porque la hacienda no tuvo el mismo peso en estas subregiones antioqueñas, que en las zonas centrales. Es de recordar que la década del veinte es crucial para la configuración de la hacienda en el Magdalena Medio.

En el espacio de estudio, este primer ciclo, que según la historiografía agraria terminaría con la promulgación de la primera ley de tierras en 1936, se extendería hasta 1947. En estas zonas se observa más bien una continuidad en el proceso de ocupación de las tierras baldías, dinámica que se expresará de manera conflictiva.

La promulgación de la ley 47 de 1926 generó un escenario propicio para que el campesinado, que ya tenía una tradición legalista desde el siglo XIX, gracias a las tempranas leyes que sobre baldíos se promulgaron y que de alguna manera los amparaba, irrumpiera con fuerza en el escenario nacional ante la posibilidad de adjudicarse las tierras que venían trabajando por décadas. Este escenario fue también aprovechado por empresarios agrícolas quienes también empezaron a colonizar las tierras más productivas al oriente de Antioquia con el fin de establecer grandes latifundios. Así, estos empresarios empezaron a comprar mejoras a los colonos y paralelamente a apropiarse de su trabajo con el fin de establecer haciendas. En esta zona los empresarios se valieron de métodos legales, pero también de la violencia para expulsar a los campesinos de sus tierras. No obstante, este proceso no fue jalonado exclusivamente por un aparato legal favorable a la colonización de tierras públicas. En Antioquia este proceso se dio de la mano de los avances en obras de infraestructura, principalmente del Ferrocarril de Antioquia 
que desde la década del veinte ya comunicaba con mayor efectividad al Magdalena Medio con Medellín.

Frente a estos procesos de expansión de los mercados basados en la producción derivada de la hacienda, los campesinos no estuvieron pasivos. Al contrario, plantearon formas de resistencia que no fueron solo las cotidianas que se dan fuera del escenario, como las propuestas por James $\mathrm{Scott}^{35}$, sino también abiertas, las cuales desafiaron abiertamente el orden impuesto, cuestionando la tenencia de la tierra y la forma en que se estaba configurando este territorio fronterizo. Estas formas de resistencia consistieron en la ocupación de terrenos y las amenazas, además, del uso de la violencia como la destrucción de cercos, sementeras y casas de habitación, y en menor medida el asesinato. No obstante, los colonos también se valieron de la jurisprudencia. Los campesinos, no operaron por fuera de los marcos del Estado, al contrario, se valieron de las leyes que los amparaban para hacer valer su derecho a la tierra. Asimismo, se valieron del aparato legal cuando eran víctimas del despojo, interponiendo querellas frente a los inspectores y jueces municipales, anhelando una intervención efectiva del Estado en la resolución de sus conflictos.

Ante este escenario de efervescencia de la cuestión agraria, la respuesta del Estado consistió en promulgar leyes, que más que en la redistribución y modificación de la tenencia de la tierra, se basaron en la expansión de la frontera agrícola. Por esta razón, la Ley 200 de 1936 no fue efectiva, a pesar de reconocer la función social de la tierra, no logró solucionar los problemas que se generaron de los procesos de colonización, pues la ocupación de baldíos siempre fue vista como una válvula de escape frente a los problemas de concentración de la tierra.

El estudio de estas dinámicas en el Magdalena Medio pone de manifiesto la interacción de diversos actores que entran en juego en el contexto de la colonización hacia las zonas de frontera, los cuales no se limitan exclusivamente a los colonos y a los empresarios agrícolas. En primer 54 lugar, se entiende que dentro del grupo de empresarios hay divisiones y

35 James Scott, Los dominados y el arte de la resistencia (México: Ediciones Era, 2000). 
contradicciones, como fue el caso de la ocupación de tierras por parte de empresarios con intereses en la ganadería y la Sociedad Agrícola y de Inmigración. Ahora bien, el campesinado no es homogéneo, las fuentes revisadas ponen de manifiesto que estos también entran en relación con otros campesinos. En este punto cabe reconocer las limitaciones metodológicas de las fuentes revisadas. Particularmente para el desarrollo de este artículo se revisaron principalmente fuentes regionales poco usadas en los estudios de historia agraria. Probablemente esto se deba a la estructura de los expedientes de baldíos, que contienen información serial que se repite de un expediente a otro (memoriales de denuncio, declaraciones juradas, inspecciones oculares), no obstante, si estos expedientes se miran con detenimiento, se ven oposiciones, querellas, copias de los juicios de tierras, en los que se pone de relieve la aparición de diversos actores que ocupan la frontera y sus conflictos. Si bien, para el caso del Magdalena Medio, los expedientes que aparecen de manera más reiterada son los de la Sociedad Agrícola y de Inmigración, también se pueden diferenciar los conflictos entre los colonos sin tierra, los campesinos pobres y algunos pequeños y medianos propietarios. Además, de la interacción que tienen con gamonales, tinterillos y abogados. Estas diferenciaciones son vitales para el avance de los estudios agrarios, en tanto permiten comprender el dinamismo y las tensiones en las fronteras internas, sus mecanismos de resolución, ya sea a través de la violencia o de la negociación, y las especificidades de cada región. Finalmente, identificar los distintos tipos de conflictos y los usos de la violencia, especialmente la violencia social popular, destaca la agencia del campesinado y sus contradicciones internas.

\section{BibLIOGRAFÍA}

\section{Fuentes Primarias}

Archivo Histórico de Antioquia (AHA), Medellín-Colombia. Secretaría de Hacienda, Minas y Baldíos, Tomo 5126, Carpeta 1, 1924.

Archivo Histórico de Antioquia (AHA), Medellín-Colombia. Secretaría de Hacienda, Minas y Baldíos, Caja 5125, Carpeta 2, 1939.

Archivo Histórico de Antioquia (AHA), Medellín-Colombia. Secretaría de Hacienda, Minas y Baldíos, Caja 5134, Carpeta 3, 1900-1942. 
Archivo Histórico de Antioquia (AHA), Medellín-Colombia. Secretaría de Gobierno, Gobierno Municipios, Tomo 435, 1935.

Archivo Histórico de Antioquia (AHA), Medellín-Colombia. Secretaría de Gobierno, Gobierno Municipios, Tomo 521, 1946.

Archivo Histórico de Antioquia (AHA), Medellín-Colombia. Diario Oficial, (Bogotá: Imprenta Oficial, 1926-1960).

Archivo Histórico Judicial de Medellín (AHJM), Medellín-Colombia. Documentos. 8736 y 8752, 1920.

\section{Fuentes Secundarias}

Álvarez Múnera, José Roberto. "Empresas rurales en Antioquia. La ganadería en el Oriente y el Magdalena Medio entre 1920 y 1960”. (Tesis de doctorado en Ciencias Sociales/ Universidad de Antioquia/2013).

Álvarez Múnera, José Roberto. Mercado, ganado y territorio: Haciendas y hacendados en el Oriente y el Magdalena Medio antioqueños (1920-1960). Medellín: Universidad de Antioquia, 2016.

Appelbaum, Nancy. "Whitening the Region: Caucano Mediation and "Antioqueño Colonization" in Nineteenth- Century Colombia".

The Hispanic American Historical Review. Duke University 79, No. 4 (1999): 631-67. www.jstor.org/stable/2518165.

Ausdal, Shawn. "Ni calamidad no panacea: Una reflexión en torno a la historiografía de la ganadería colombiana". En El poder de la carne. Historias de ganaderías en la primera mitad del siglo XX en Colombia, editado por Alberto Florez-Malagón. Bogotá: Pontificia Universidad Javeriana, 2012.

Ausdal, Shawn. "Un mosaico cambiante: notas sobre una geografía histórica de la ganadería en Colombia, 1850-1950”. En El poder de la carne. Historias de ganaderías en la primera mitad del siglo XX en Colombia. Bogotá: Pontificia Universidad Javeriana, 2008.

Christie, Keith H. "Antioqueño Colonization in Western Colombia: A Reappraisal". The Hispanic American Historical Review. Duke University 58 No. 2 (1978): 260-83.

Goicovic, Igor. "Consideraciones teóricas sobre la violencia social en Chile (1850-1930)”. Última Década No. 21 (2005): 121-45. 
Gómez Giraldo, Lucella. Las fronteras de Antioquia. Aspectos físicos, jurídicos, históricos, económicos y socioculturales. Medellín: Universidad de Antioquia, Fondo editorial FCSH, 2005.

González, José Jairo, y Elsy Marulanda. Historias de frontera. Colonización y guerra en el Sumapaz. Bogotá: CINEP, 1990.

Inmigración, Sociedad Agrícola y de. "Compilación de los principales documentos sobre la Sociedad Agrícola y de Inmigración”. Medellín: Imprenta Oficial, 1921.

Jaramillo, Roberto Luis. "La otra cara de la colonización antioqueña hacia el sur", s. f.

Jiménez, Michael. 'Traveling Far in Grandfather's Car: The Life Cycle of Central Colombian Coffee Estates. The Case of Viotá, Cundinamarca (1900-1930)". Hispanic American Historical Review. Duke University 69 No. 2 (1989): 185-219.

Jiménez, Michael F. "En el festín de la civilización: los límites de la hegemonía de los hacendados a comienzos del siglo XX en Colombia". Innovar. Revista de ciencias administrativas y sociales (1996):113-33.

LeGrand, Catherine. "Campesinos asalariados en la zona bananera de Santa Marta". Anuario colombiano de historia social y de la cultura, No. 11 (1983): 235-50.

LeGrand, Catherine. Colonización y protesta campesina en Colombia. 1850-1950. Bogotá: Universidad Nacional de Colombia, 1988.

Londoño, Rocío. Juan de la Cruz Varela. Sociedad y política en la región de Sumapaz (1902-1984). Bogotá: Universidad Nacional de Colombia, 2011.

Marulanda, Elsy. Colonización y conflicto. Las lecciones del Sumapaz. Bogotá: Tercer Mundo Editores, IEPRI, 1991.

Meertens, Donny. Ensayos sobre tierra, violencia y género. Hombres y mujeres en la historia rural de Colombia. 1930-1990. Bogotá: Universidad Nacional de Colombia, 2000.

Osorio Silva, Ligia María. "Tierras nuevas y la construcción del Estado en Brasil y Argentina”. América Latina en la Historia Económica, No. 25 (2006): 45-71.

Palacios, Marco. ¿De quién es la tierra? Propiedad, politización y protesta campesina en la década de 1930. Bogotá: Fondo de Cultura Económica, Universidad de Los Andes, 2011. 
Palacios, Marco. El café en Colombia, 1850-1970. Una historia económica, social y política. Bogotá: El Colegio de México- El Áncora Editores, 1983.

Parsons, James, Antioqueño Colonization in Western Colombia. Berkeley: University of California Press, 194.

Ramírez Bacca, Renzo. "Formación de una hacienda cafetera: mecanismos de organización empresarial y relaciones administrativo-laborales: el caso de La Aurora (Líbano-Colombia), 1882-1907'. Cuadernos de Desarrollo Rural 42 No. 42 (1999): 83-115.

Samper, Mario. Generations of Settlers. Rural households and markets on the Costa Rican frontier, 1850-1935. San Francisco: Westview Press. Dellplain Latin American Studies No. 26, 1990.

Scott, James. Los dominados y el arte de la resistencia. México: Ediciones Era, 2000.

Tovar Pinzón, Hermes. "Los baldíos y el problema agrario en la Costa Caribe de Colombia (1830-1900)". Fronteras 1, No. 1 (1997): 3555.

Vega Cantor, Renan. "Las luchas agrarias en Colombia en la década de 1920". Cuadernos de desarrollo rural No. 52 (2004): 9-47. http://revistas.javeriana.edu.co/index.php/desarrollorural/article/view/1264.

Yarrington, Doug. "Public Land Settlement, Privatization, and Peasant Protest in Duaca, Venezuela , 1870-1936". Hispanic American Historical Review. Duke University 74 No. 1 (1994): 33-61.

Para citar este artículo: Henao Holguín, Diana. "Empresarios agrícolas y campesinos colonos: colonización y conflicto agrario en la frontera antioqueña (1926-1947)", Historia Caribe Vol. XVI No. 39 (Julio-Diciembre 2021): 23-58. DOI: https://doi.org/10.15648/ hc.39.2021.2951 